\title{
Factors Associated with Students' Daily Fruit and Vegetable Recommendation at Umm Al-Qura University
}

\author{
Heba Althubaiti \\ Home Science Education Department, Nutrition Unit, Umm Al-Qura University, Al-Lith Campus, Al-Lith, KSA \\ Email: hathubaiti@uqu.edu.sa
}

How to cite this paper: Althubaiti, H. (2022) Factors Associated with Students' Daily Fruit and Vegetable Recommendation at Umm Al-Qura University. Food and Nutrition Sciences, 13, 124-135. https://doi.org/10.4236/fns.2022.132012

Received: January 10, 2022

Accepted: February 11, 2022

Published: February 14, 2022

Copyright ( 2022 by author(s) and Scientific Research Publishing Inc. This work is licensed under the Creative Commons Attribution International License (CC BY 4.0).

http://creativecommons.org/licenses/by/4.0/

\section{(c) (i) Open Access}

\begin{abstract}
Introduction: There is a lack of the awareness in the fruit and vegetable (F \& V) recommendation among Saudi society. Although the known facts of the benefits of F \& V on health, information on Saudi society following the advised recommendation whether by WHO or local are still unknown. Aim: This cross-sectional study aims to examine the perception of $\mathrm{F} \& \mathrm{~V}$ intake among students at Umm Al-Qura University and to assess if they follow these recommendations of F \& V locally and internationally. Method: Students from Umm Al-Qura University participated in this study ( $\mathrm{n}=98$, age between 18 - 55). All data were collected using short online survey via Online survey-Survey Monkey in 2019. Result: 55\% students were not aware of these recommendations whereas $45 \%$ were aware of WHO recommendation. The majority of students $53 \%$ have less than two portions a day of $\mathrm{F} \& \mathrm{~V}$. Only $14 \%$ have between two to four portions a day. $32 \%$ do not eat any portion of F \& V daily. 59\%, 14\%, 5\% of students believe that they should have five, seven, more than seven portions a day for being healthy respectively. Maintaining health, reducing the risk for chronic disease and providing essential vitamins and minerals to the body were all reasons why students believe that they should have F \& V everyday by $71 \%$. Busy lifestyle, F \& V cost, lack of the awareness about the health benefits, dislike of the taste, some F \& $\mathrm{V}$ spoiled easily were all factors affecting eating $\mathrm{F} \& \mathrm{~V}$ daily. Conclusion: University students need educational and nutritional campaigns to spread the awareness about the health benefits of F \& V. Most importantly the ministry of health should support those campaigns to increase students' awareness and build a healthy society with a good habit.
\end{abstract}

\section{Keywords}

Fruit Intake, Veg Intake, F \& V Recommendation, Students, Umm Al-Qura 
University

\section{Introduction}

Diets rich in vegetables and fruits assist in reducing various chronic health conditions, which are the leading causes of death globally. According to a study conducted by the Centre for Diseases Control and Prevention, one in ten adults eat enough vegetables and fruits daily. World Health Organization, and the involvement of other health care organizations, have played a critical role in creating awareness on the importance of vegetable and fruit intake towards the development of individual health [1].

A study conducted by the Nurse Health Professionals revealed that eating two servings of vegetables and fruits is linked with life longevity. Additionally, the study compared the participants who consumed two servings of vegetables and fruits daily and five servings. The results showed that $15 \%$ reduced risks associated with stroke and heart diseases, 10\% decreased cancer rates, and 35\% reduced respiratory diseases [2].

According to Mello Rodrigues fruits and vegetables are natural nutrient sources, and they are essential for maintaining individual health [3].

Low vegetable and fruit intake are associated with obesity and overweight since they consist of low glycaemic value, soluble fiber, high nutrient density, and low energy density. These are the critical elements in body weight management and lowering risks linked to obesity. A study conducted by Dhandevi and Jeewon in 2015 shows it is significant for students to consume a rich diet with high vegetables to reduce occurrences of chronic diseases and maintain the body weight and chronic diseases [4]. The global trend indicates a declining situation in the consumption patterns of vegetables and fruits among students. Research conducted by Vereecken et al. (2015) among college students in Germany showed that $80 \%$ of students preferred daily consumption of vegetables and fruits. However, the study also showed that fruit and vegetable intake was still low [5]. In this regard, students transitioning from tertiary school to university change their eating habits, resulting in various health complications prevalent in many students in the University and College [6]. Examples of health complications include overweight, obesity, and other complications associated with poor diet, especially vegetables and fruits. The main concern involves the patterns of food consumption linked to nutritional risks to many students and staff. Hung states that food choices and eating behavior in universities are triggered by various aspects, including weight change, energy demand changes, social-cultural factors, including culture and food prices [7].

Students' perception of fruits and vegetable intake varies differently, while some of the perception trends show adequate consumption, and others illustrate a decline in consumption patterns. Vereecken conducted a study in 2015 on 
student consumption of fruit and vegetable in Arkansas [5]. They concluded on the existence of various attributed factors that contribute to students' negative perceptions, including a personal risk and perceived factors related to behaviors on consumption [5].

Gender plays a critical role in vegetable and fruit consumption by students and staff. A study consumed by Dhandev and Jeewon in 2015 showed that female students' consumption rates were high compared to male students [4]. The study further provided significant discussion that the consumption level could be lower than the recommended level despite females consuming more vegetables and fruits than the male students.

Consumption of fruits and vegetables in colleges and universities relies on the availability of the products since staff members and students prefer consuming different varieties of vegetables and fruits. A study conducted by Borgi in 2016 to investigate the aspects that influence students' consumption of fruits and vegetables showed inadequate provision of vegetables and fruits in colleges that have led to low consumption levels among the staff and the students [8].

Additionally, a study conducted by Mello Rodrigues in 2019 using self-reports and food frequency questionnaires in Kankasa University showed that students and staff preferred vegetables and fruits if only there various varieties in the institution. Lifestyle changes have contributed significantly to the low preference for vegetable and fruit intake [3]. Dhandev and Jeewon in 2015 state that students' diet intake revolves around undesirable practices, including fast food and increased sugar intake, leading to lower consumption of vegetables and fruits [4].

Students lack significant knowledge concerning vegetable and fruit consumption leading to decreased intake of fruits. A study conducted based on a self-report and frequency questionnaire on more than 300 students in college showed that approximately $75 \%$ of the participants lacked significant knowledge concerning the health benefits of vegetable and fruit consumption. Though some students knew the significance of consuming fruits and vegetables to their health, they rarely practiced the daily recommended intake.

Additionally, attitudes and demographic aspects play a critical role in influencing vegetable and fruit consumption. The relationship between attitudes and demographic factors about the barriers and benefits of vegetables and fruits consumption was examined by Hung [7]. The results were significant and showed various aspects with different vegetable and fruit consumption variations, including students' consumption behavior and lack of knowledge.

Some of the prevalent, deliberating, and widespread nutritional disorders worldwide include physical, mental, and congenital disabilities, blindness, weak immune systems. High mortality rates result from a lack of minerals and vitamins in vegetables and fruits [9]. Frequent intake of vegetables and fruits has proven to enhance the psychological wellbeing of an individual in a short duration [10]. Vegetables and fruits are significant aspects of a healthful fit. Their importance is not limited to the psychological health of an individual, which is 
one reason why many people prefer high consumption of fruits and vegetables daily. A study conducted by Guillaumie,, and Vézina-Im confirmed that young adults provided with enough vegetables and fruits for two weeks experienced an increase in vitality and motivation [6]. Intake of vegetables and fruits is linked to reducing some health-related issues such as blood pressure, heart disease, and diabetes. This cross-sectional study aims to examine the Saudi perception of F \& $\mathrm{V}$ intake among at Umm Al-Qura University and to assess if they follow these recommendations of $\mathrm{F} \& \mathrm{~V}$ locally and internationally.

Study aim: Examine the perception of F \& V intake among students and staff at Umm Al-Qura University Assess if they follow these recommendations of F \& V locally and internationally.

\section{Methods}

\subsection{Study Population}

Students from Umm Al-Qura University participated in this study $(\mathrm{n}=98$, age between 18 - 35). The majority of the participants were from Al-Leith City. All Sociodemographic characteristics (students age, education level, their income level) were collected. This study was conducted in 2020 and there was delay in writing the paper due to COVID 19 pandemic.

\subsection{F \& V Perception Online Survey}

The questionnaire contains five main questions regarding $\mathrm{F} \& \mathrm{~V}$ perception and was short and easy to answer. A copy of the questionnaire online link in Arabic language is found as follow: https://www.surveymonkey.com/r/SJ6WHYC.

The study link was emailed to female students at the university-Al-Leith branch via university email from the researcher to students directly. The students then were given full decision for participation.

The study questionnaire was designed based on previous literatures however, small adjustments were added to the study questionnaire to meet the study society differences. These questions are as follow:

1a. Factors affecting students reaching $\mathrm{F} \& \mathrm{~V}$ recommendation.

2a. Why students think that they should have the daily F \& V recommendation in their meals?

3a. Students were also asked about the following questions: $3 \mathrm{a} 1$. Whether they know/ hear about the WHO daily F \& V recommendation; 3a2. How many portions of $\mathrm{F} \& \mathrm{~V}$ they eat daily; 3a3. How many portions of $\mathrm{F} \& \mathrm{~V}$ they believe it is the optimal portions for promoting health?

The validity and reliability of the questionnaire was tested prior to the distribution of the study questionnaire. The validity of the questionnaire was tested by sending the study research questions-questionnaire to proofreader to ensure it is clear and grammatically free from mistakes to avoid any ambiguity. Amended version was then to specialist in nutrition and food science for a final assessment before distributing the questionnaire. 
The reliability of the questionnaire was tested to ensure consistency, stability and accuracy of the questionnaire by pilot study with a small group of students $\mathrm{n}$ $=20$ who were asked to complete the questionnaire and adjustments were made to the questionnaire where necessary for clarification. Cronbach's alpha was also employed to assess the internal consistency. A value of alpha $>0.7$ is indicated the internal reliability for the questionnaire. In this study the result of Cronbach's alpha was 0.83 indicating that the instrument of $\mathrm{F} \& \mathrm{~V}$ questionnaire was internally reliable and consistent.

\subsection{Data Collection}

All data were collected using short online survey via Online survey-Survey Monkey in 2019. All data were collected after about 4 weeks from the first day of distributing the online survey. Data were cleaned first before calculating the percentage to ensure the accuracy of the result.

\subsection{Data Analysis and Ethical Considerations}

SPSS was used in all of the online survey in order to calculate the percentage.

This study was approved by Umm Al-Qura university-Al Leith Branch-home science education departments specifically by the dean of the college before distributing the online questionnaire. No further departmental ethics approval was required due to the noninvasive nature of this study because it has no risk to participants.

\section{Result}

\subsection{Study Population and Factors Affecting Students Reaching Fruit and Vegetable Recommendation}

98 female students at Umm Al-Qura University-Al Leith Branch were asked about questions that are related to their perception on $\mathrm{F} \& \mathrm{~V}$ recommendation. The majority of them aged between $18-25$.

In the research, 98 participants (University Students) were asked about different factors affecting the students' reaching fruits and vegetable recommendations. The results obtained from the research were as follows. First, approximately $53.06 \%$ of the University students $(n=52)$ indicated that their busy life-quick lifestyle is the most crucial factor that impacts their reach the fruit and vegetable recommendation. Further, it was established that approximately $45.92 \%$ of participants $(n=45)$ believed that most did not reach the fruit and vegetable recommendation because it was not part of their food habits since a young age. Another factor that impacted the fruit and vegetable reach was awareness. From the results obtained, approximately $20.41 \%$ of the respondents $(n=20)$ believed that they failed to reach fruits and vegetable recommendations because they were not aware of their existence. Again, $24.49 \%$ of the respondents $(n=24)$ believed that they never reached out to the fruit and vegetable recommendation since it spoils too quickly. 
Other observations obtained indicated that approximately $11.22 \%$ of respondents $(n=11)$ believed that those fruits and vegetables are too costly and have undesirable taste; therefore, they do not prefer their daily recommendation. Again, approximately $10.20 \%(n=10)$ agreed that all of the above-mentioned factors act as a catalyst in reaching the Fruits and vegetable recommendation. Lastly, approximately $3.06 \%$ of respondents mentioned other reasons, such as the lack of a variety of fruits and vegetables as the catalyst for the reach of the fruit and vegetable recommendation.

\subsection{Why Do Students Believe That They Should Have the Daily Recommendation of Fruit and Vegetable?}

In determining the participants' perception on why the daily recommendation of fruit and vegetable is crucial in their diet, the following results were obtained. First, it was established that approximately $10.20 \%(n=10)$ believed that it was vital to have daily recommendations of fruits and vegetables in their diet because it contributes to a healthy and balanced diet. Further, it was established that approximately $13.37(n=13)$ believed that having a daily recommendation of fruits and vegetable provide them with vitamins and minerals. Again, $4.08 \%$ of respondents indicated that daily recommendation of fruits and vegetables is vital in the human diet because it boosts human immune; thus, reducing chronic disease risks. Lastly, it was established that approximately $70.41 \%$ of the respondents indicated that daily recommendation of fruits and vegetables in the human diet is vital since it supports the above-mentioned reasons. Therefore, it is recommended to have a daily recommendation of fruits and vegetables. Overall, the majority of the population agrees that daily recommendations of fruits and vegetables improve human immune. In contrast, it was established that approximately $2.04 \%$ of respondents did not know the reasons why they should have fruit and vegetable in their daily meals. In other words, they do not understand the importance of fruits and vegetables in the daily recommendation.

\subsection{General Questions Related to Fruit and Vegetable Daily Recommendation}

\section{Q3a. Students were asked whether they heard about the recommendation} that is recommended by the WHO?

The results on students' perception about the WHO recommendation on a diet were as follows; approximately $55.10 \%(n=54)$, which is the majority of the respondents, indicated that they did not hear anything about the fruits and vegetable recommendation from WHO. This implied that WHO had minimal impacts on influencing the student's diet habits. Further, it was established that approximately $38.78 \%(n=38)$ have heard about the WHO recommendations; however, they indicated that there were no details. Similarly, it can be established that WHO has minimal impacts on diet recommendation, especially fruit and vegetable eating habits, to students. Lastly, it was established that the least 
population of approximately $6.12 \%(n=6)$ have heard about the WHO fruit and vegetable recommendation, and they have had more details about these recommendations. From these findings, it can be concluded that WHO recommendations, especially on fruit and vegetable diet, are not significant to most students since the majority of them do not understand the respective recommendations or have minimal understanding about the WHO recommendations.

Q3b. Students were asked about how many portions of fruit and vegetable they eat daily?

In determining participants' perception about the number of portions of fruits and vegetables that they require to eat daily, approximately 98 participants were engaged. From the target population, approximately $53.06 \%(n=52)$ believed that students are supposed to eat less than two fruits and vegetable portions a day. On the other side, approximately $31.63 \%(\mathrm{n}=31)$ believed that it was not important to have any fruits and vegetable portions daily. Again, it was established of 98 students, $14.29 \%$ argued that it was okay for them to have between 2 - 4 fruits and vegetable portions daily, while $01.02 \%(\mathrm{n}=1)$ stated that having more than six fruits and vegetable portions daily was the ideal option.

Q3c. Students were asked about how many portions of fruit and vegetable they think that is important to have daily in order to promote their health?

From the research, it was established that approximately 98 students participated in sharing their perception about how many portions of fruit and vegetable they think that is important to have daily to promote healthy lifestyles. Out of the 98 participants, 58 participants (59.18\%) indicated that having between 2 5 fruits and vegetable portions a day promotes good health, whereas else $14.29 \%$ $(\mathrm{n}=14)$ believed that between $5-7$ fruits and vegetable portions a day promote good health. Another observation obtained from the research is that approximately $12.24 \%(\mathrm{n}=12)$ thought that having less than two fruits and vegetable portions a day would promote good health. Approximately $9.18 \%(n=9)$ believed that there existed no connection between having fruits and vegetable portions a day and promoting good health. Lastly, approximately $5.10 \%$ of participants $(\mathrm{n}=5)$ thought that having more than seven fruits and vegetable portions a day promotes good health.

\section{Discussion}

Factors like quick lifestyle, a lack of proper health habits beginning at a young age, and reduced awareness are significant challenges the analysis found concerning reaching daily recommendations regarding fruit and vegetable intake. Eliason in 2020 noted that one source of reduced awareness concerning the study's recommendations is the parental perceptions of healthfulness that influence children's eating habits [11]. For instance, $45.92 \%$ of the study recorded a lack of constituency in fruit and vegetable daily recommendations through adopted practices, in most cases, from parents or guardians. The analysis also recorded a mismatch of healthfulness between parents and children. Eliason 
highlight that $44 \%$ - $65 \%$ of parent held the perception that their children consume daily recommendations despite the percentage presenting a mismatch through analysis of the children [11]. The mismatch originates from children's adaptation of dietary behaviors that disengage from healthier perceptions. Such perceptions play a crucial role in the neglect of consumption of fruits and vegetables for substituting with added sugar diets [12]. Slavin and Lloyd in 2012 also explained that the quick lifestyle engaged throughout higher education accounts for at least $53.06 \%$ of the study's analysis [13]. The study noted that most students prefer high-fat diets based on energy concentration over required vitamins, proteins, minerals, and energy. Some reasons contributing to the rise in such preferences include a lack of availability, satiety, social transmission, and sensory preferences integrated into food consumption.

At least $20.41 \%$ of the participants recorded reduced awareness regarding the benefits of consuming fruits and vegetables. Keim, Stewart, and Voichick in 1997 noted that, even though most youths are aware of the need to take fruits and vegetables, majority lack clarity regarding the health benefits of the practice, especially on daily doses [14]. The study by Alkazemi and Salmean in 2021 also supports the lack of awareness among students by analyzing a focus group of Kuwait Students [15]. The authors insist that a lack of clarity regarding F/V intake proportions for assessing and managing different functions makes it challenging for the group to maintain consistency in practice. Citrowske notes that factors like high F/V costs, lack of access to such products based on demographic factors, and lack of variety of F/V contribute to the $11.22 \%$ and $3.06 \%$ of the results discovered in the analysis [16].

\subsection{The Need for Daily F/V Recommendations}

A total of $70.41 \%$ of the participants in the study supported the need for engaging and following daily F/V recommendations for purposes like the issuance of a balanced and healthy diet, provision of minerals and vitamins, and protection from chronic diseases. Giampietro, Bugin, and Trestini in 2021 note that health consciousness is a significant determinant factor that students use to advance healthy lifestyles while avoiding chronic diseases [17]. Amao in 2018 also insists that health consciousness can help students make effective choices regarding consumption habits. Realizing basic concepts regarding health benefits offered by fruits and vegetables, as noted by the authors, is an approach for offering students variety and more information concerning proper F/V recommendations [18]. Hartman in 2013 also insisted that students' awareness regarding F/V recommendations stems from the realization of the role of such practices in advancing weight management and advanced health outcomes [19]. Since the practices prove beneficial for students' health, they act as key reinforcing concepts for positive support and influence. A review of the previous ten years regarding F/V recommendations among students done by Rodrigues also noted that students offer an upbeat adaptation of such functions based on the per- 
ceived benefits of following issued recommendations [20]. Similar results remain evident in the study by Batis in 2020 [21]. The authors noted that the individuals' levels of self-perception of distinct F/V consumption levels are similar to the results based on the students' health perceptions used in the analysis. De Carvalho, de Menezes, and Lopes in 2018 also second the notion by noting the role of mechanisms like literature in advancing F/V access and consumption [22]. Students' perceptions of consuming the adequate F/V amounts and varieties depend on information mechanisms and practices to assist with contemplation and engagement of proper eating habits.

Support from institutions like the World Health Organization in 2020 and Harvard Medical School in 2018 assisted the study in recording an average of $38.78 \%$ of parties who implement and used such F/V recommendation strategies [1] [23]. On the other hand, Sattar and Forouhi in 2021 found a gap between knowledge and the implementation of $\mathrm{F} / \mathrm{V}$ recommendations among different participants [24].

The $53.06 \%$ of the participants having less than two F/V portions a day in the study, as noted by the American Heart Association in 2021, need adequate information regarding the benefits of such practices to advance followership and participation in such dietary plans [25]. The study by van den Bogerd in 2019 also insists that integrating intervention plans like sufficient foods and literature to teachers and students can increase awareness levels higher than $12.24 \%$ found in the study [26]. Also, Hanson in 2019 supported the implementation of F/V recommendation strategies for offering students cooking confidence and frequency matching adequate meals plans for health gain [27]. Barad in 2019 offered associations regarding F/V recommendations and eating habits to note the importance of raising awareness on the matter among students [28]. Teschl in 2018 also note that, since most students demonstrate no preference to F/V recommendations, the implementation of self-assessment practices and strategies can ensure effective F/V intake [29]. For instance, Whitnall in 2019 offered relations between $\mathrm{F} / \mathrm{V}$ intake and high academic performance [30]. Using such analysis in the study can assist in offering precise and practical recommendations for students. Also, the study by Opoku-Acheampong in 2018 helps elaborate $\mathrm{F} / \mathrm{V}$ patterns among students to offer practical and suitable recommendations for the study [31].

\subsection{Study Limitation}

There are two limitations for this study. First, this study was intended to be conducted on both staff and students at the University of Umm Al-Qura unfortunately, few numbers of staff who participated in this study and to avoid biased data in the result the answers for those staff were excluded and not analyzed. Secondly, the majority of the participants were female students apart of a very small number of male students who were excluded from analyzing their data to avoid any biased result. 


\subsection{Conclusion and Recommendation}

Saudi students demonstrated a low level on the health benefits of F \& V. People need educational and nutritional campaigns to spread the awareness about the health benefits of F \& V. Most importantly the ministry of health should support those campaigns to increase people awareness and build a healthy society with a good habit.

\section{Conflicts of Interest}

The author declares no conflicts of interest regarding the publication of this paper.

\section{References}

[1] World Health Organization (2020) Promoting Fruit and Vegetable Consumption. https://www.euro.who.int/en/health-topics/disease-prevention/nutrition/activities/t echnical-support-to-member-states/promoting-fruit-and-vegetable-consumption

[2] Wang, D.D., Li, Y., Bhupathiraju, S.N., Rosner, B.A., Sun, Q., Giovannucci, E.L., Rimm, E.B., Manson, J.E., Willett, W.C., Stampfer, M.J. and Hu, F.B. (2021) Fruit and Vegetable Intake and Mortality: Results from 2 Prospective Cohort Studies of US Men and Women and a Meta-Analysis of 26 Cohort Studies. Circulation, 143, 1642-1654. https://doi.org/10.1161/CIRCULATIONAHA.120.048996

[3] Mello Rodrigues, V., Bray, J., Fernandes, A.C., Luci Bernardo, G., Hartwell, H., Secchi Martinelli, S., Lazzarin Uggioni, P., Barletto Cavalli, S. and Proença, R.P.D.C. (2019) Vegetable Consumption and Factors Associated with Increased Intake among College Students: A Scoping Review of the Last 10 Years. Nutrients, 11, 1634. https://doi.org/10.3390/nu11071634

[4] Dhandevi, P.E.M. and Jeewon, R. (2015) Fruit and Vegetable Intake: Benefits and Progress of Nutrition Education Interventions-Narrative Review Article. Iranian Journal of Public Health, 44, 1309.

[5] Vereecken, C., Pedersen, T.P., Ojala, K., Krølner, R., Dzielska, A., Ahluwalia, N., Giacchi, M. and Kelly, C. (2015) Fruit and Vegetable Consumption Trends among Adolescents from 2002 to 2010 in 33 Countries. The European Journal of Public Health, 25, 16-19. https://doi.org/10.1093/eurpub/ckv012

[6] Guillaumie, L., Godin, G. and Vézina-Im, L.A. (2010) Psychosocial Determinants of Fruit and Vegetable Intake in an Adult Population: A Systematic Review. International Journal of Behavioral Nutrition and Physical Activity, 7, 1-12.

https://doi.org/10.1186/1479-5868-7-12

[7] Hung, H.C., Joshipura, K.J., Jiang, R., Hu, F.B., Hunter, D., Smith-Warner, S.A., Colditz, G.A., Rosner, B., Spiegelman, D. and Willett, W.C. (2014) Fruit and Vegetable Intake and Risk of Major Chronic Disease. Journal of the National Cancer Institute, 96, 1577-1584. https://doi.org/10.1093/jnci/djh296

[8] Borgi, L., Muraki, I., Satija, A., Willett, W.C., Rimm, E.B. and Forman, J.P. (2016) Fruit and Vegetable Consumption and the Incidence of Hypertension in Three Prospective Cohort Studies. Hypertension, 67, 288-293. https://doi.org/10.1161/HYPERTENSIONAHA.115.06497

[9] Bertail, P. and Caillavet, F. (2012) Fruit and Vegetable Consumption Patterns: A Segmentation Approach. American Journal of Agricultural Economics, 90, 827-842. https://doi.org/10.1111/j.1467-8276.2008.01138.x 
[10] Rasmussen, M., Krølner, R., Klepp, K. I., Lytle, L., Brug, J., Bere, E. and Due, P. (2016) Determinants of Fruit and Vegetable Consumption among Children and Adolescents: A Review of the Literature. Part I: Quantitative Studies. International journal of Behavioral Nutrition and Physical Activity, 3, 1-19.

[11] Eliason, J., Acciai, F., DeWeese, R.S., Vega-Lopez, S. and Ohri-Vachaspati, P. (2020) Children's Consumption Patterns and Their Parent's Perception of a Healthy Diet. Nutrients, 12, 1-12. https://doi.org/10.3390/nu12082322

[12] Okagbare, T.E. and Naidoo, S. (2020) Parents' Perception of Their Role in the Prevention of Inadequate Consumption of Fruit and Vegetables among Adolescents in South Africa. South African Dental Journal, 75, 235-240. https://doi.org/10.17159/2519-0105/2020/v75no5a1

[13] Slavin, J.L. and Lloyd, B. (2012) Health Benefits of Fruits and Vegetables. Advances in Nutrition, 3, 506-516. https://doi.org/10.3945/an.112.002154

[14] Keim, K.S., Stewart, B. and Voichick, J. (1997) Vegetable and Fruit Intake and Perceptions of Selected Young Adults. Journal of Nutrition Education, 29, 80-85. https://doi.org/10.1016/S0022-3182(97)70159-6

[15] Alkazemi, D. and Salmean, Y. (2021) Fruit and Vegetable Intake and Barriers to Their Consumption among University Students in Kuwait: A Cross-Sectional Survey. Journal of Environmental and Public Health, 2021, Article ID: 9920270. https://doi.org/10.1155/2021/9920270

[16] Citrowske, A. (2020) Predictors of Fruit and Vegetable Intake among University Students.

https://commons.und.edu/cgi/viewcontent.cgi?article $=4263 \&$ context=theses

[17] Giampietri, E., Bugin, G. and Trestini, S. (2021) On the Association between Risk Attitude and Fruit and Vegetable Consumption: Insight from University Students in Italy. Agricultural and Food Economics, 20, 1-16. https://doi.org/10.1186/s40100-021-00194-4

[18] Amao, I. (2018) Health Benefits of Fruits and Vegetables: Review from Sub-Saharan Africa. In: Importance of Quality Vegetables to Human Health, IntechOpen, London, 33-53. https://www.intechopen.com/chapters/59450 https://doi.org/10.5772/intechopen.74472

[19] Hartman, H., Wadsworth, D.P., Penny, S. and Van Assema, P. (2013) Psychosocial Determinants of Fruit and Vegetable Consumption among Students in a New Zealand University: Results of Focus Group Interviews. Appetite, 65, 35-42. https://doi.org/10.1016/j.appet.2013.02.005

[20] Rodrigues, V.M., et al. (2019) Vegetable Consumption and Factors Associated with Increased Intake among College Students: A Scoping Review of the Last 10 Years. Nutrients, 11, 1634. https://doi.org/10.3390/nu11071634

[21] Batis, C., et al. (2020) Self-Perception of Dietary Quality and Adherence to Dietary Recommendations among Mexican Adults. Nutrition Journal, 19, 59. https://doi.org/10.1186/s12937-020-00573-5

[22] Menezes, M.C., Diez Roux, A.V. and Souza Lopes, A.C. (2018) Fruit and Vegetable Intake: Influence of Perceived Food Environment and Self-Efficacy. Appetite, 127, 249-256. https://doi.org/10.1016/j.appet.2018.05.011

[23] Harvard Medical School (2018) Getting Your Five a Day. Harvard Health Publishing, Boston.

https://www.health.harvard.edu/staying-healthy/getting-your-five-a-day

[24] Sattar, N. and Forouhi, N.G. (2021) More Evidence for 5-a-Day for Fruit and Vegetables and a Greater Need for Translating Dietary Research Evidence to Practice. 
Circulation, 143, 1655-1658.

https://doi.org/10.1161/CIRCULATIONAHA.121.053293

[25] American Heart Association (2021, March 1) The Right "5-a-Day" Mix Is Two Fruit and Three Vegetable Servings for Longer Life.

https://www.sciencedaily.com/releases/2021/03/210301084519.htm

[26] Van den Bogerd, N., Maas, J., Seidell, J.C. and Dijkstra, S.C. (2019) Fruit and Vegetable Intakes, Associated Characteristics and Perceptions of Current and Future Availability in Dutch University Students. Public Health Nutrition, 22, 1951-1959. https://doi.org/10.1017/S136898001800174X

[27] Hanson, A.J., Kattelmann, K.K., McCormack, L.A., Zhou, W., Brown, O.N., Horacek, T.M., Shelnutt, K.P., Kidd, T., Opoku-Acheampong, A., Franzen-Castle, L.D. and Olfert, M.D. (2019) Cooking and Meal Planning as Predictors of Fruit and Vegetable Intake and BMI in First-Year College Students. International Journal of Environmental Research and Public Health, 16, 2462. https://doi.org/10.3390/ijerph16142462

[28] Barad, A., Cartledge, A., Gemmill, K., Misner, N.M., Santiago, C.E., Yavelow, M. and Langkamp-Henken, B. (2019) Associations between Intuitive Eating Behaviors and Fruit and Vegetable Intake among College Students. Journal of Nutrition Education and Behavior, 51, 758-762. https://doi.org/10.1016/j.jneb.2019.03.010

[29] Teschl, C., Nössler, C., Schneider, M., Carlsohn, A. and Lührmann, P. (2018) Vegetable Consumption among University Students: Relationship between Vegetable Intake, Knowledge of Recommended Vegetable Servings, and Self-Assessed Achievement of Vegetable Intake Recommendations. Health Education Journal, 77, 398-411. https://doi.org/10.1177/0017896917751833

[30] Whitnall, M.C., Patterson, A.J., Burrows, T.L. and Hutchesson, M.J. (2019) Higher Diet Quality in University Students Is Associated with Higher Academic Achievement. Journal of Human Nutrition and Dietetics, 32, 321-328. https://doi.org/10.1111/jhn.12632

[31] Opoku-Acheampong, A.A., Kidd, T., Adhikari, K., Muturi, N. and Kattelmann, K. (2018) Assessing Physical Activity, Fruit, Vegetable, and Sugar-Sweetened Beverage Intake Patterns of College Students in Kansas. Journal of Nutrition Education and Behavior, 50, 977-983. https://doi.org/10.1016/j.jneb.2018.02.001 